\title{
Aspectos epidemiológicos e distribuição de casos de esquistossomose no Nordeste brasileiro no período de 2010 a 2017
}

\author{
Epidemiological aspects and distribution of \\ cases of schistosomosis in the Northeast \\ Brazil from 2010 to 2017
}

\section{Bianca Leão Barreto' (1) Claudia Gonçalves Lobo² (1)}

${ }^{1}$ Autora principal para correspondência. Faculdade de Ciências Humanas de Olinda (Olinda). Recife, Brasil. bianquinhaleao@gmail.com ${ }^{2}$ Faculdade de Ciências Humanas de Olinda (Olinda). Recife, Brasil. claudia67lobo@gmail.com

\begin{abstract}
RESUMO | OBJETIVO: Analisar aspectos epidemiológicos de casos de esquistossomose na região do Nordeste brasileiro notificados no Sistema Nacional de Agravos e Notificação (SINAN) no período de 2010 a 2017. METODOLOGIA: Trata-se de estudo epidemiológico descritivo observacional. A coleta dos dados secundários foi realizada através do SINAN e submetidos a análise estatística descritiva, por meio de frequência absoluta e frequência relativa, apresentados na forma de gráficos e tabelas utilizando o Excel 2016. RESULTADOS: No período, foram notificados 10.431 casos, sendo os anos de 2010, seguido de 2014 e 2015, os que mais se destacaram. Os estados do Nordeste com maior número de casos foram Bahia, com 5.183 casos, Pernambuco, com 2.330, Paraíba, com 857, e Sergipe, com 769. A análise do perfil biológico dos infectados, no que se refere ao sexo, mostrou que a maior proporção de infectados é do sexo masculino (54\%) e as faixas etárias com maiores índices de infecção, foram 20 a 39 anos com 34,68\% e de 40 a 59 anos com 28,89\%. CONCLUSÃo: A esquistossomose é um grande problema de saúde pública, portanto, é indispensável ações e divulgação das regiões endêmicas para construção de intervenções sobre o controle da doença, enfatizando o atendimento e fazendo busca ativa da população.
\end{abstract}

DESCRITORES: Esquistossomose. Schistosoma mansoni. Esquistossomose mansoni. Epidemiologia.

\begin{abstract}
OBJECTIVE: To analyze epidemiological aspects of schistosomiasis cases in Brazil's Northeastern region notified in the National Diseases and Notification System (SINAN) from 2010 to 2017. METHODOLOGY: This is an observational descriptive epidemiological study. The collection of secondary data was carried out through SINAN and submitted to descriptive statistical analysis, through absolute frequency and relative frequency, presented in graphs and tables using Excel 2016. RESULTS: There were 10,431 notifications; the years that stood out were 2010, followed by 2014 and 2015. The Northeast states with a high prevalence of cases were Bahia with 5.183 cases, Pernambuco with 2.330, Paraíba with 857, and Sergipe with 769. The analysis of the biological profile of those infected, with regard to gender, showed that the highest proportion of infected people is male (54\%), and the age groups with the highest infection rates were 20 to 39 years old with $34.68 \%$ and 40 to 59 years old with $28.89 \%$. CONCLUSION: Schistosomiasis is a major public health problem. Therefore, it is essential to promote and disseminate endemic regions to build interventions to control the disease, emphasize care, and actively seek out the population.
\end{abstract}

DESCRIPTORS: Schistosomiasis. Schistosoma mansoni. Schistosomiasis mansoni. Epidemiology. 


\section{Introdução}

A esquistossomose é uma doença parasitária causada pelo Schistosoma mansoni. Trata-se de uma doença endêmica e um grande problema de saúde pública ${ }^{1}$. A doença está relacionada com a pobreza e o baixo desenvolvimento econômico, afetando principalmente os municípios pobres, rurais e as populações agrícolas e pesqueiras $²$.

A esquistossomose é uma doença relacionada com as coleções hídricas, apresentando-se nas formas: aguda ou crônica² ${ }^{2}$. De acordo com o Ministério da Saúde, entre os fatores de riscos para a transmissão do S. mansoni, pode-se destacar a precariedade de saneamento ambiental e domiciliar, a carência de educação em saúde para as populações de riscos e os movimentos de pessoas nas áreas endêmicas ou permanente ${ }^{3}$.

A esquistossomose não está restrita a regiões rurais. Devido ao aumento do ecoturismo e a migração populacional, a doença expandiu-se e sofreu modificações ambientais facilitando a sua transmissão 2 . Os caramujos estão presentes em acúmulos de água doce constante, como: barragem, locais de irrigação, rios, lagoas, esgotos e brejos; já os locais temporários são: os canais de drenagem de águas pluviais, terrenos alagadiços, valas e córregos ${ }^{3}$. Diante disto, o Nordeste apresenta condições ambientais, socioeconômicas e culturais que favorecem a disseminação do parasita e do hospedeiro intermediário, obtendo como consequência econômica e sanitária considerável de responsabilidade do progresso do estado 4 .

Nas regiões litorâneas, os criadouros do caramujo se localizam principalmente no peridomicílio e na estação chuvosa os focos onde estão transbordam e os caramujos contaminados são trazidos para as ruas e interior das residências, provocando uma contaminação de boa parte da população ${ }^{5}$. Desta forma, o indivíduo se torna susceptível a contaminação quando entra em contato com águas contaminadas, na qual usam os locais para banhos, pescas, lavagem de roupa e louças ${ }^{6}$.

A Organização Mundial de Saúde presume que a esquistossomose afete 240 milhões de pessoas em todo o mundo e mais de 700 milhões residem em áreas endêmicas com risco de contaminação ${ }^{7}$. A esquistossomose é considerada endêmica em 74 países, e classificada como a $3^{\circ}$ causa de morbidade nos países em desenvolvimento na África, América do Sul, Caribe, Oriente Médio e Ásiå․․

A esquistossomose tem alta incidência na África e Leste do Mediterrâneo, chegando às mediações do Delta do Nilo e dos países como Egito e Sudão. Quando se trata da América do Sul, a doença se sobressai no território do Caribe, Venezuela e o Brasil. No Brasil, as regiões mais afetadas pela esquistossomose são o Nordeste e Sudeste, pois existe o contato direto com o molusco transmissor, mesmo a doença tendo casos positivos em todos os estados. As áreas endêmicas são: Maranhão, Alagoas, Bahia, Paraíba, Pernambuco, Rio Grande do Norte, Sergipe, Minas Gerais e Espírito Santo. Já as áreas com transmissão focal são: Pará, Piauí, Ceará, Rio de Janeiro, São Paulo, Paraná, Santa Catarina, Goiás, Distrito Federal e Rio Grande do Sul? .

O molusco do gênero Biomphalaria tem 34 espécies identificadas até o momento, dentre eles 22 estão nas Américas e 12 na África, Madagascar e Oriente Médio?. No Brasil, foram encontradas 11 espécies e uma subespécie, cujas três espécies são conhecidas como hospedeiras naturais do S. mansoni, sendo elas $B$. glabrata, B. tenegophila e $B$. straminea. As espécies $B$. peregrina, $B$. amazônica e $B$. cousini são espécies hospedeiras potenciais, que podem ser infectadas artificialmente em laboratórios ${ }^{3}$.

As espécies dos caramujos que predominam no Brasil são três, Biomphalaria glabrata, Biomphalaria straminea e Biomphalaria tenagophila. Essas espécies estão distribuídas geograficamente no território brasileiro e são responsáveis pela disseminação da esquistossomose $\mathrm{e}^{10}$.

Considerando que o Nordeste é uma região propícia para disseminação da esquistossomose, pois existem fatores, falta de saneamento ambiental e sanitário, que favorecem a contaminação e distribuição do parasita pelas coleções hídricas, ocasionando a propagação do Schistosoma mansoni. Este trabalho tem relevância, já que visa conhecer a distribuição geográfica da doença no Nordeste brasileiro no período de 2010 a 2017, fazendo o mapeamento da região nordeste e identificando as áreas de maiores abrangências de indivíduos contaminados. Neste contexto, tem como objetivo analisar os aspectos epidemiológicos de casos de esquistossomose na região do nordeste brasileiro notificados ao Sistema Nacional de Agravos e Notificação (SINAN) no período de 2010 a 2017. 


\section{Método}

Trata-se de um estudo epidemiológico descritivo observacional. A pesquisa foi realizada através de levantamentos de dados secundários na base de dados dos casos notificados no Sistema Nacional de Agravos e Notificação (SINAN).

A população do estudo foi composta pelos dados cadastrados no SINAN de indivíduos infectados pelo Schistosoma mansoni na região do Nordeste brasileiro. Foram incluídos todos os casos positivos de esquistossomose no Nordeste, nos anos de 2010 a 2017.

A coleta de dados foi realizada no SINAN entre os anos de 2010 a 2017, sendo referentes a toda região do nordeste brasileiro. As variáveis utilizadas do SINAN foram: ano de notificação, região de notificação, região/uf de notificação, unidade federativa de notificação, sexo, faixa etária e casos confirmados.

A análise desses dados foi realizada por frequências absolutas e frequência relativa. Foram elaborados tabelas e gráficos no Microsoft Excel 2016, possibilitando melhor visualização e análise dos dados.

O referido estudo não necessitou de liberação de Comitê de Ética e Pesquisa (PEC) para a sua realização, pois utilizou dados secundários de domínio público.

\section{Resultados}

O total de casos confirmados e disponibilizados pelo SINAN, no período de 2010 a 2017, foi 10.384. O ano que apresentou maior número de casos da doença foi 2010, seguido de 2014 e 2015 . Ocorreu uma diminuição entre os anos de 2011 a 2013, havendo um aumento considerável nos anos de 2014 e 2015, e um declínio significativo nos anos de 2016 e 2017 (Gráfico 1).

Gráfico 1. Distribuição da esquistossomose na região do nordeste brasileiro no período de 2010 a 2017

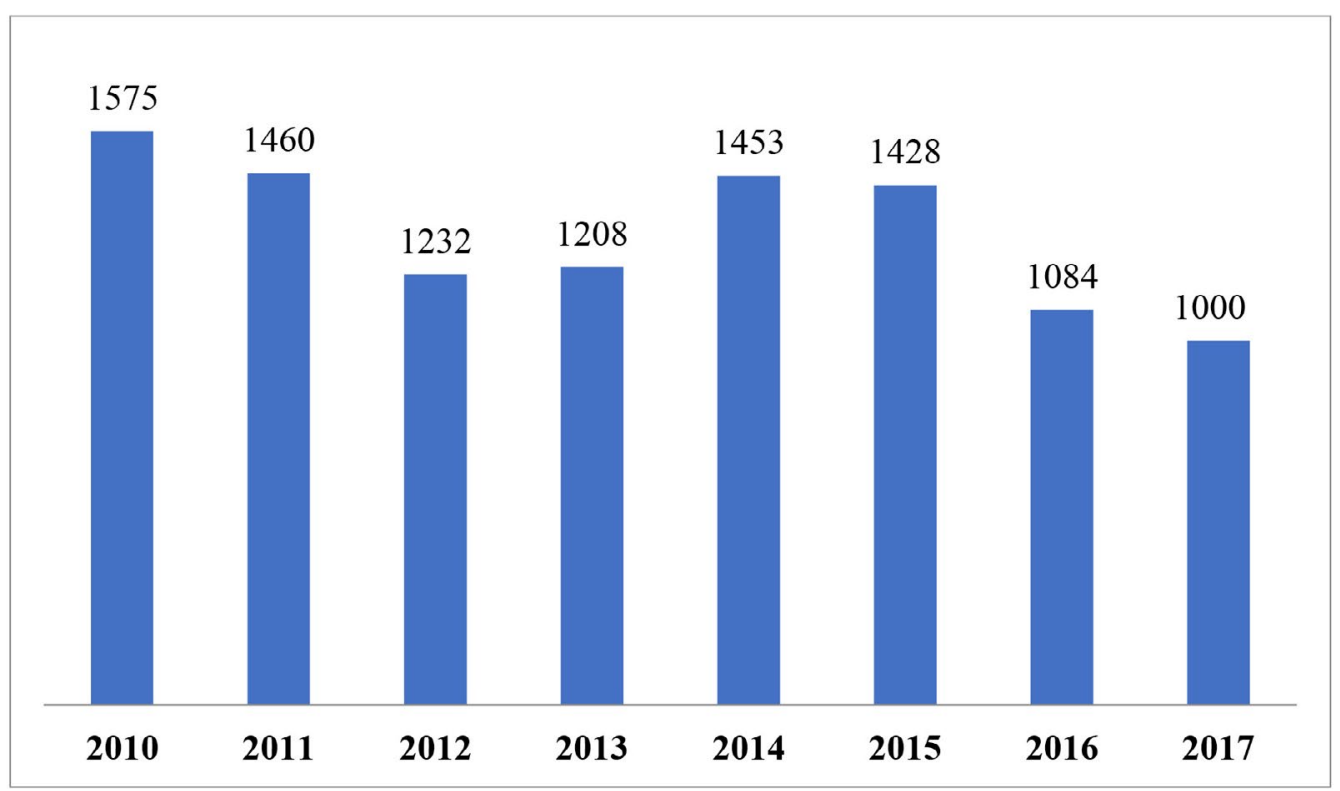

Fonte: SINAN/PCE, 2017 
Dentre os nove estados do Nordeste, os que apresentaram maior número de casos de esquistossomose, no período de 2010 a 2017, foram a Bahia com 5.183 casos, Pernambuco com 2.330 casos, Paraíba com 857 casos e Sergipe com 769 casos. O único estado que possui poucas notificações é o Piauí; nos anos de 2015 e 2016 não houve notificações, mas em 2017 houve apenas 1 caso, registrando um total de 13 casos durante esse período (Tabela 1).

Tabela 1. Distribuição de esquistossomose por estado da região Nordeste brasileiro no período de 2010 a 2017

\begin{tabular}{|c|c|c|c|c|c|c|c|c|c|}
\hline Estados & 2010 & 2011 & 2012 & 2013 & 2014 & 2015 & 2016 & 2017 & Total \\
\hline Alagoas & 103 & 48 & 28 & 34 & 35 & 49 & 110 & 61 & 468 \\
\hline Bahia & 745 & 724 & 614 & 684 & 841 & 703 & 440 & 432 & 5.183 \\
\hline Ceará & 86 & 17 & 19 & 22 & 27 & 35 & 24 & 30 & 260 \\
\hline Maranhão & 73 & 68 & 59 & 12 & 19 & 15 & 9 & 78 & 333 \\
\hline Paraíba & 81 & 159 & 154 & 38 & 114 & 85 & 121 & 105 & 857 \\
\hline Pernambuco & 366 & 319 & 256 & 286 & 305 & 363 & 242 & 193 & 2.330 \\
\hline Piauí & 0 & 6 & 3 & 2 & 1 & 0 & 0 & 1 & 13 \\
\hline Rio Grande do & 48 & 24 & 25 & 32 & 14 & 27 & 26 & 22 & 218 \\
\hline \multicolumn{10}{|l|}{ Norte } \\
\hline Sergipe & 64 & 95 & 74 & 98 & 97 & 151 & 112 & 78 & 769 \\
\hline Total & 1.566 & 1.460 & 1.232 & 1.208 & 1.453 & 1.428 & 1.084 & 1.000 & 10.432 \\
\hline
\end{tabular}

Conforme a frequência relativa, Pernambuco possui $22,33 \%$ dos casos notificados, os anos que se destacaram foram 2010, com 3,51\%, 2014, com 2,92\%, e 2015, com 3,48\%, evidenciando uma instabilidade dos casos de esquistossomose no estado. Sergipe é um dos estados que houve domínio da situação, os anos que evidenciaram elevados índices das notificações foram em 2013 com 0,94\%, 2014 com 0,93\%, 2015 com 1,45\% e 2016 com 1,07\%, revelando que houve crescimento da infecção. Dentre todos os estados do Nordeste, a Bahia foi o estado que apresentou percentuais elevados de positividade dos casos, sendo responsável por 49,69\% dos casos entre 2010 a 2017, os anos que houve prevalência das notificações foram em 2010 com 7,14\%, 2011 com 6,94\% e 2014 com 8,06\% (Tabela 2).

Tabela 2. Distribuição do percentual de casos de esquistossomose por estado da região Nordeste brasileiro no período de 2010 a 2017

\begin{tabular}{|c|c|c|c|c|c|c|c|c|c|}
\hline Estados & 2010 & 2011 & 2012 & 2013 & 2014 & 2015 & 2016 & 2017 & Total \\
\hline Alagoas & $0,98 \%$ & $0,45 \%$ & $0,26 \%$ & $0,32 \%$ & $0,33 \%$ & $0,46 \%$ & $1,05 \%$ & $0,58 \%$ & $4,43 \%$ \\
\hline Bahia & $7,17 \%$ & $6,97 \%$ & $5,91 \%$ & $6,58 \%$ & $8,09 \%$ & $6,77 \%$ & $4,23 \%$ & $4,16 \%$ & $49,26 \%$ \\
\hline Ceará & $0,82 \%$ & $0,16 \%$ & $0,18 \%$ & $0,21 \%$ & $0,25 \%$ & $0,33 \%$ & $0,23 \%$ & $0,28 \%$ & $2,46 \%$ \\
\hline Maranhão & $0,70 \%$ & $0,65 \%$ & $0,56 \%$ & $0,11 \%$ & $0,18 \%$ & $0,14 \%$ & $0,08 \%$ & $0,74 \%$ & $3,16 \%$ \\
\hline Paraíba & $0,77 \%$ & $1,53 \%$ & $1,47 \%$ & $0,36 \%$ & $1,09 \%$ & $0,81 \%$ & $1,16 \%$ & $1,01 \%$ & $8,20 \%$ \\
\hline Pernambuco & $3,52 \%$ & $3,07 \%$ & $2,46 \%$ & $2,75 \%$ & $2,93 \%$ & $3,49 \%$ & $2,33 \%$ & $1,85 \%$ & $22,40 \%$ \\
\hline Piauí & $0 \%$ & $0,05 \%$ & $0,02 \%$ & $0,01 \%$ & $0,01 \%$ & $0 \%$ & $0 \%$ & $0,01 \%$ & $0,10 \%$ \\
\hline $\begin{array}{l}\text { Rio Grande do } \\
\text { Norte }\end{array}$ & $0,45 \%$ & $0,23 \%$ & $0,23 \%$ & $0,30 \%$ & $0,13 \%$ & $0,025 \%$ & $0,24 \%$ & $0,21 \%$ & $2,04 \%$ \\
\hline Sergipe & $0,61 \%$ & $0,91 \%$ & $0,70 \%$ & $0,93 \%$ & $0,93 \%$ & $1,44 \%$ & $1,07 \%$ & $0,74 \%$ & $7,33 \%$ \\
\hline Total & $15,02 \%$ & $14,02 \%$ & $11,79 \%$ & $11,57 \%$ & $13,94 \%$ & $13,69 \%$ & $10,39 \%$ & $9,58 \%$ & $100 \%$ \\
\hline
\end{tabular}

Fonte: SINAN, 2017.

De acordo com a análise do perfil biológico dos pacientes infectados com esquistossomose no Nordeste, no que se refere ao gênero, foram observados uma grande proporção de infectados do sexo masculino, com um percentual de $54,18 \%$ em relação aos indivíduos do sexo feminino que foi de $45,82 \%$. No entanto, não houve diferenças elevadas entre ambos os sexos no período de 2010. No período de 2011 a 2017, fica evidente o quanto o sexo masculino sobressai em relação ao sexo feminino (Gráfico 2). 


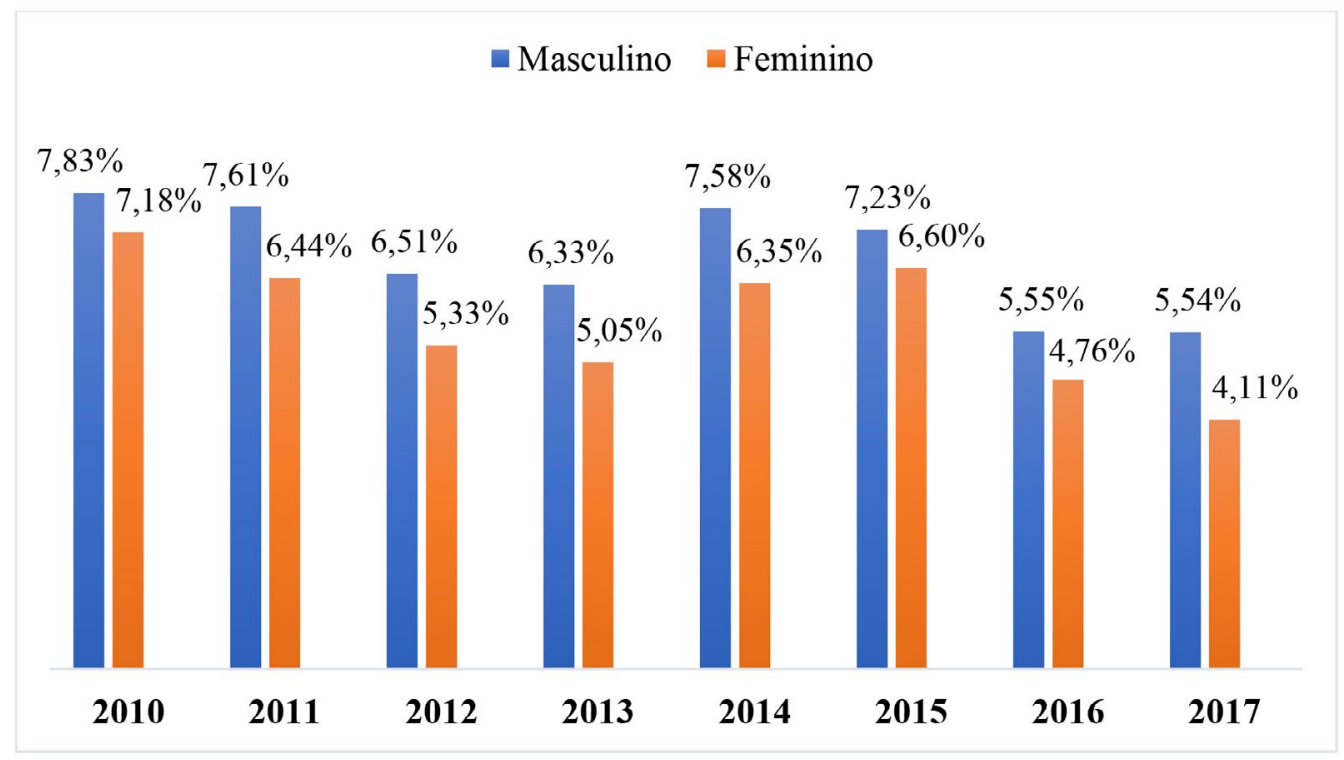

Fonte: SINAN, 2017.

De acordo com as análises da variável faixa etária dos indivíduos infectados com esquistossomose na região do Nordeste, observou-se que as faixas etárias com maiores índices de pacientes com esquistossomose estão entre 20 a 39 anos de idade (34,68\%) e de 40 a 59 anos (28,89\%). Vale ressaltar que a infecção atingiu todas as idades, sendo essas: em branco/ignorados com 0,02\%, menores de 1 ano com 0,80\%, de 1 a 4 anos com 0,83\%, de 5 a 9 anos com 4,02\%, de 10 a 14 anos foi de 7,04\%, de 15 a 19 anos de idade com 6,74\%, de 20 a 39 anos com 34,68\%, de 40 a 59 anos com 28,89\%, de 60 a 69 anos de idade com 5,08\%, de 65 a 69 anos com 4,47\%, de 70 a 79 com $5,25 \%$ e de 80 ou mais com 2,18\% de indivíduos que contraíram a doença (Gráfico 3).

Gráfico 3. Distribuição indivíduos infectados com esquistossomose na região do Nordeste brasileiro, de acordo a faixa etária no período de 2010 a 2017

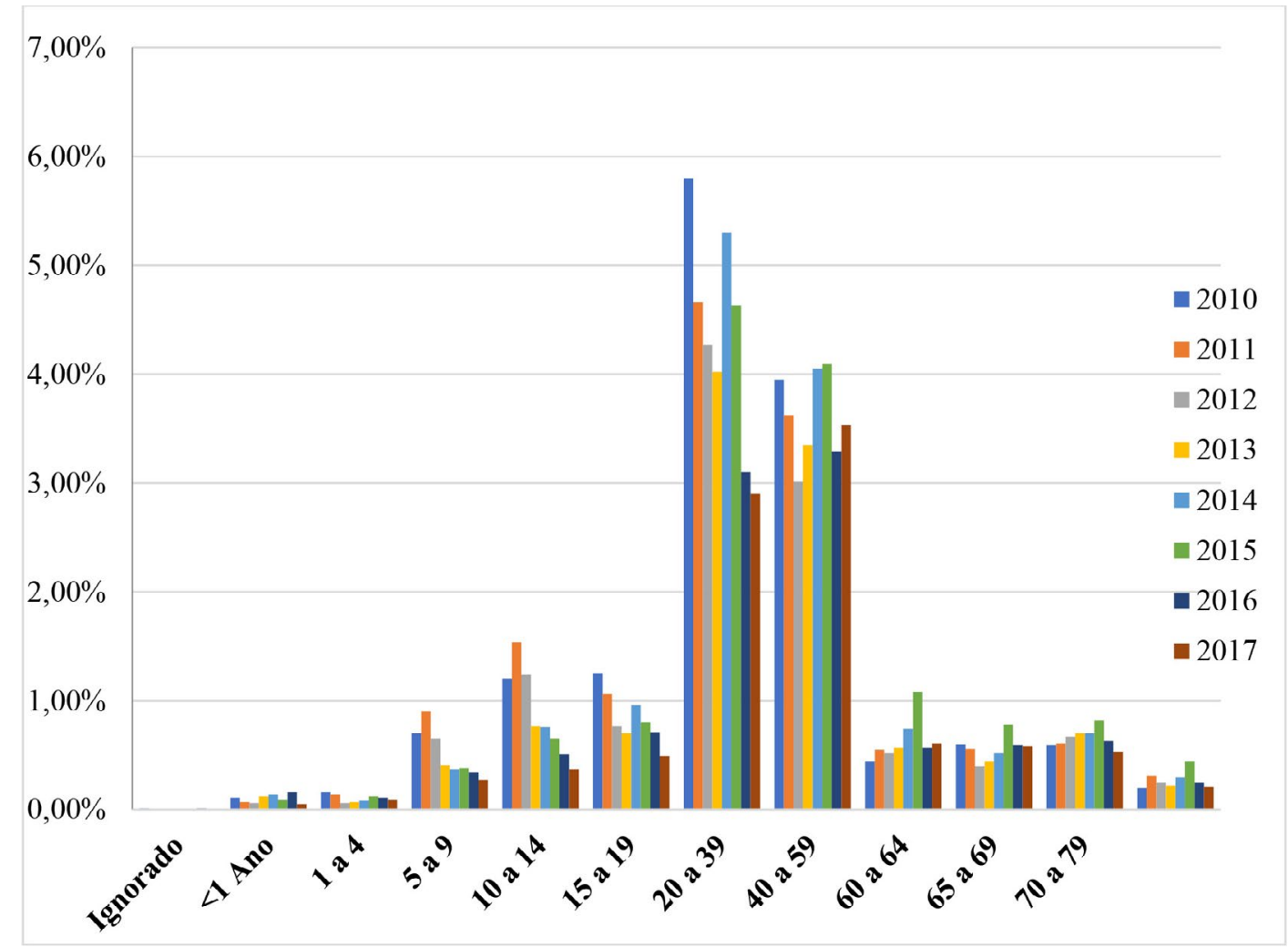

Fonte: SINAN, 2017. 


\section{Discussão}

No Brasil, a esquistossomose está presente em todas as regiões; consequentemente, as regiões que apresentam maiores números dos casos em ordem decrescente são o Sudeste, com 65.209 casos, seguido do Nordeste, com 10.319 casos, logo após vem o Norte, com 468 casos, seguido do Centro-Oeste, com 449 casos, e em último lugar vem o Sul, com 417 casos, totalizando 76.862 casos em todo o país. Dentre todas as macrorregiões, a região do Nordeste está no $2^{\circ}$ lugar no ranking da esquistossomose, sendo equivalente a $13 \%$ da totalidade dos casos confirmados no período de 2010 a $2017^{11}$.

As regiões que apresentam alta prevalência dos casos é o Sudeste e Nordeste, desta maneira, a região do Nordeste apresenta maior distribuição dos casos de esquistossomose do que outras regiões em decorrência de alguns fatores. Como exemplo, pode-se citar a disseminação do Biomphalaria spp., hospedeiro intermediário para o S. mansoni. A região Nordeste fornece um habitat ideal para o Biomphalaria spp., sendo comum de ser encontrado nas coleções hídricas naturais e nas coleções hídricas artificias. Nesses locais, é observada a presença da vegetação macrófita, principalmente as plantas herbáceas que servem para alimentação, substrato, proteção, diminuindo a luz do sol e temperatura, e na deposição das desovas, favorecendo assim a sobrevivência do caramujo, ${ }^{3,12}$.

O Nordeste é a região brasileira que possui a maior costa litorânea do país, por ser uma área que possui várias coleções hídricas, tornando-se um local propicio para transmissão da Schistosoma mansoni. Como é uma doença negligenciada e a região possui índices de pobreza, proporcionando a contaminação e proliferação do caramujo, torna-se fácil a sua disseminação, uma vez que é só entrar em contato com água doce que possua o caramujo infectado ${ }^{4}$.

A esquistossomose é uma doença que tem relação com a escassez ao acesso à água potável e saneamento básico precário. Estima-se que 290,8 milhões de pessoas em todo o mundo foram contaminadas, necessitando de tratamento, mas apenas 97,2 milhões foram tratadas 2 . Infere-se que o cenário de carência no tratamento nos esgotos e nas águas, a falta de saneamento básico, a dificuldade de entrada nos serviços de saúde e as baixas condições socioeconômicas, eventualmente contribui de forma determinantes para o adoecimento da população do Nordeste.
Os estados de Alagoas, Bahia, Pernambuco e Sergipe possuem condições ecológicas e de organização espacial que proporciona a transmissão da esquistossomose, que são elas: a presença do caramujo B. glabrata e temperaturas elevadas em boa parte do ano, favorecendo o desenvolvimento do miracídio. Os fatores socioeconômicos e intrínsecos do ser humano influenciam na manutenção da esquistossomose. A qualidade da água afeta na manutenção do caramujo na biossistema, quando a poluição se instala, ocasionada por fatores antrópicos que podem levar à mutação de caramujos mais resistentes ${ }^{1}$.

O estado de Alagoas possui 70 municípios endêmi$\cos ^{13}$, e os dados evidenciam que o ano que houve alta prevalência dos casos foi em 2010 com 0,99\% e 2016 com 1,05\%. De acordo com o IBGE ${ }^{14}$, apenas $10 \%$ de todo estado possui o Plano Municipal de Saneamento Básico para abastecimento de água e esgotamento sanitário, ocasionando condições precárias favoráveis para disseminação da doença.

O estado de Pernambuco possui áreas endêmicas rurais e litorâneas. A irradiação dos esgotos nos rios, lagoas e valas possibilita a criação de ambientes insalubres que são favoráveis à transmissão da doença. O foco da doença no estado é localizado na região metropolitana, na zona da mata e nas cidades vizinhas ao agreste pernambucano ${ }^{15}$.

O estado de Sergipe possui 51 municípios endêmicos, em 2017, havia prevalência de $5,5 \%$ da população ${ }^{16}$. Dentre todos os estados do Nordeste, a Bahia foi o estado que apresentou percentuais elevados de positividade dos casos, sendo responsável por $49,69 \%$ dos casos, entre 2010 a 2017, os anos em que houve prevalência das notificações foram em 2010 , com $7,14 \%$, 2011, com 6,94\%, e 2014, com 8,06\%. O grau de risco para transmissão da esquistossomose na Bahia pode-se apresentar da seguinte forma: 128 municípios (30,7\%) são endêmicos, 123 municípios (29,5\%) são focais e 166 municípios (39,8\%) são indenes ${ }^{17}$.

No presente estudo, observou-se que o sexo masculino apresentou maior proporção de infectados. A maior prevalência da infecção no sexo masculino pode ser explicada devido o homem está mais exposto aos riscos da doença, com hábitos de pesca e agricultura, evidenciando o contato direto com a água, podendo a mesma está contaminada ${ }^{18}$. Os anos que apresentaram maior percentual foram em 2010, 2011 e em 2014 e 2015, embora não tenha sido aumentos expressivos. 
Em relação à faixa etária, foi observado que predominou a dos adultos. Neste caso, considera-se a possibilidade por serem economicamente ativos, pois esses indivíduos estão mais susceptíveis às áreas contaminadas, devido a exposição pelos trabalhos em lavouras, pescas e utilização de águas contaminadas para fins domésticos e lazer.

Neste estudo, evidenciou que a região do Nordeste apresenta acúmulo de muitas águas paradas, lagoas, valas de esgotos, canais, rios e vegetações, o que ocasiona um local ideal propício para a disseminação do parasita. As regiões possuem áreas precárias de saneamento básico e políticas de saúde pública, que, junto com a propagação do hospedeiro intermediário, torna o processo de urbanização desordenada, favorecendo a manutenção e expansão territorial da esquistossomose por intermédio dos focos de transmissão para esquistossomose ${ }^{1}$.

As notificações são realizadas através da ficha de investigação de esquistossomose no SINAN. Desta maneira, as limitações são referentes aos levantamentos secundários devido à perda dos dados, informações pendentes e/ou erros na coleta, podendo gerar inconsistência pertinente ao estudo. Outra limitação encontrada foi a indisponibilidade de informações sobre o saneamento básico da população e as atividades que lhes deixam vulneráveis à infecção. Os dados averiguados são referentes à população do Nordeste com diagnóstico confirmado, sendo impossível ter interferências no estudo.

\section{Conclusão}

Os achados presentes na pesquisa, analisados entre os anos de 2010 a 2017, evidenciam que o número de casos de esquistossomose no Nordeste brasileiro foi maior no ano de 2010, seguido dos anos de 2014 e 2015. Dentre os nove estados do Nordeste, os que apresentaram maior número de casos de esquistossomose foram em ordem decrescente Bahia, Pernambuco, Paraíba e Sergipe. O perfil biológico revelou que o sexo masculino teve a maior proporção dos infectados e as faixas etárias com maiores índices foram de 20 a 39 anos e de 40 a 59 anos de idade.
A esquistossomose é um grande problema de saúde pública, portanto, é importante a realização de ações de prevenção e educação sanitária, sendo indispensável a divulgação das regiões endêmicas para construção de intervenções sobre o controle da doença, enfatizando o atendimento nessas áreas e fazendo a busca ativa da população.

\section{Contribuições das autoras}

Lobo CG participou da concepção, delineamento, busca e análise estatística dos dados da pesquisa, interpretação dos resultados e interpretação dos dados. Barreto BL participou da concepção, delineamento, busca e análise estatística dos dados da pesquisa, interpretação dos resultados, interpretação dos dados, coleta de dados da pesquisa e redação final do artigo científico.

\section{Conflitos de interesses}

Nenhum conflito financeiro, legal ou político envolvendo terceiros (governo, empresas e fundações privadas, etc.) foi declarado para nenhum aspecto do trabalho submetido (incluindo, mas não se limitando a subvenções e financiamentos, participação em conselho consultivo, desenho de estudo, preparação de manuscrito, análise estatística, etc.).

\section{Referências}

1. Ministério da Saúde (Brasil). Guia de vigilância em saúde [Internet]. 3a ed. Brasília: Ministério da saúde; 2019. Disponível em: https://bvsms.saude.gov.br/bvs/publicacoes/guia_vigilancia saude 3ed.pdf

2. World Health Organization. Schistosomiasis [Internet]. Suíça: World Health Organization; 2020. [citado em 2021 mar 6]. Disponível em: https://www.who.int/news-room/fact-sheets/ detail/schistosomiasis

3. Ministério da Saúde (Brasil). Vigilância da Esquistossomose Mansoni: diretrizes técnicas [Internet]. 4a ed. Brasília: Ministério da saúde; 2014. Disponível em: http://bvsms.saude.gov.br/bvs/ publicacoes/vigilancia_esquistossome_mansoni_diretrizes. tecnicas.pdf

4. Freitas J, Carvalho J, Carlos L, Alves M, Silva S, Lara FV, et al. Esquistossomose, uma doença no contexto da saúde pública brasileira. NOVA: Revista Científica [Internet]. 2014;2(2):52-4. Disponível em: https://bit.ly/3e3ev8y 
5. Gomes E, Leal-Neto OB, Albuquerque J, Silva HP, Barbosa CS. Schistosomiasis transmission and environmental change: a spatio-temporal analysis in Porto de Galinhas, Pernambuco--Brazil. Int J Health Geogr. 2012;11:51. https://doi. org/10.1186/1476-072x-11-51

6. Rocha TJM, Santos MCS, Lima MVM, Calheiros CML, Wanderley FS. Aspectos epidemiológicos e distribuição dos casos de infecção pelo Schistosoma mansoni em municípios do Estado de Alagoas, Brasil. Rev Pan-Amaz Saude. 2016;7(2):27-32. http://dx.doi. org/10.5123/S2176-62232016000200003

7. World Health Organization. Schistosomiasis (Bilharzia) [Internet]. Suíça: World Health Organization; 2018. [citado em 2020 out 12]. Disponível em: https://www.who.int/health-topics/ schistosomiasis\#tab=tab

8. Olveda DU, Li Y, Olveda RM, Lam AK, Chau TN, Harn DA, et al. Bilharzia: Pathology, Diagnosis, Management and Control. Trop Med Surg. 2013;1(4):135. https://doi.org/10.4172/23299088.1000135

9. Majoros G, Fehér Z, Deli T, Földvári G. Establishment of Biomphalaria tenagophila snails in Europe. Emerg Infect Dis. 2008;14(11):1812-4. https://dx.doi.org/10.3201\%2Feid1411.080479

10. Zanardi VS. Prevalência de infecção de Biomphalaria glabrata infectados por schistosoma mansoni em coleções hídricas de Salvador, Bahia - Brasil [dissertação] [Internet]. Salvador: Universidade Federal da Bahia; 2018. Disponível em: https://www. arca.fiocruz.br/handle/icict/30506

11. Datasus. Esquistossomose - casos confirmados notificados no sistema de informação de agravos de notificação - Brasil [Internet]. Ministério da Saúde; 2017. [citado 2020 out 27]. Disponível em: http://tabnet.datasus.gov.br/cgi/tabcgi. exe?sinannet/cnv/esquistobr.def
12. Standley CJ, Goodacre SL, Wade CM, Stothard JR. The population genetic structure of Biomphalaria choanomphala in Lake Victoria, East Africa: implications for schistosomiasis transmission. Parasit Vectors. 2014;7:524. https://doi.org/10.1186/ s13071-014-0524-4

13. Governo do Estado de Alagoas. Secretaria de Estado da Saúde. Esquistossomose [Internet]. Alagoas: Governo do Estado de Alagoas; 2018 [citado 2021 Mar 7]. Disponível em: http://cidadao. saude.al.gov.br/esquistossomose/

14. Instituto Brasileiro de Geografia e Estatística. Pesquisa nacional de saneamento básico [Internet]; 2017 [citado em 2020 nov 29]. Disponível em: https://cidades.ibge.gov.br/brasil/al// pesquisa/30/1

15. Barbosa CS, Gomes EL, Loyo RM, Cavalcanti MI, Silva IE, Almeida AS, et al. Ambientes turísticos insalubres e transmissão da esquistossomose em Pernambuco, Brasil. Rev. Ambient. Agua. 2018;13:1-10. http://dx.doi.org/10.4136/ambi-agua.2151

16. Governo do Estado de Sergipe. Secretaria de Estado da Saúde. Esquistossomose: Sergipe possui 51 municípios considerados endêmicos [Internet]. 2017. [citado em 2020 dez 2]. Disponível em: https://bit.ly/3wKAtj7

17. Governo do Estado da Bahia. Secretaria da Saúde. Boletim epidemiológico da esquistossomose - Bahia, 2017 [Internet]. 2017. [citado em 2020 Dez 7]. Disponível em: http://www. saude.ba.gov.br/wp-content/uploads/2017/11/2017-Boletimepidemiol\%C3\%B3gico-esquistossimose-n.-01.pdf

18. Araujo KCGM, Resendes APC, Souza-Santos R, Silveira Júnior JC, Barbosa CS. Análise espacial dos focos de Biomphalaria glabrata e de casos humanos de esquistossomose mansônica em Porto de Galinhas, Pernambuco, Brasil, no ano 2000. Cad de Saúde Pública. https://doi.org/10.1590/S0102-311X2007000200017 